\section{OPTICAL DESIGN IN INSTRUMENTS}

Instrumental Optics

By G. A. Boutry. Translated by R. Auerbach. Pp. xvi +544. (London: Hilger and Watts, Ltd., 1961.) $168 s$.

7

HE first thing that should be said about this rather expensive book is that the quality of production is outstandingly good. A great deal of attention has clearly been paid to the choice of type, to the setting out of the tables and the mathematics, and to the clarity of the diagrams, in which the essential information is boldly portrayed while the non-essentials are ruthlessly omitted. All this, combined with the quality of the paper and the striking red and black cover, makes it a book which from the asthetic point of view alone is a delight to possess.

The next thing that needs to be said is that the title gives a rather misleading impression of the contents. There is considerably more straight lens theory in its 22 chapters than might be expected in a book on instrumental optics. The scope of the book can best be judged from the titles of the five sections into which it is divided, dealing with: principles; optical systems with symmetry of revolution; systems with symmetry about a plane; vision and image formation in optical instruments; and main types of optical instruments. Only in the final section can the author be said really to come to grips with optical instruments, more particularly in the case of microscopes. The elegance of the diagrams is also best exemplified in this section, with a very simple but effective illustration (Fig. 360) showing how the exposure spreads through a photographic emulsion, as especially noteworthy.

It might have been expected that a book on instrumental optics would include chapters on interference and polarization and their use in optical instrumentation. Then, too, the special problems associated with, say, optical surveying instruments or spectrophotometers might have been discussed. But perhaps to ask for more is itself a tribute to what the author and translator have already provided.

Special mention should be made of the section entitled "Systems with Symmetry about a Plane". The chapter here on trains of refracting prisms should be particularly helpful; a second rather unusual chapter in this section discusses the symmetry and displacement of the image produced by various sequences of reflecting surfaces; while the third chapter covers the relatively unfamiliar subject of cylindrical lenses.

The original French text was written during the War years $1940-44$, so that optical developments which have taken place during the past twenty years are not discussed. At certain points, therefore, there is a slightly dated outlook, as for example, in the reference on p. 320 to the techniques being developed for producing anti-reflexion coatings. This situation has been met by footnote references given by the translator to more up-to-date publications. Other examples are the Stiles-Crawford effect and eye movements which would be given greater prominence in a modern discussion of perception through visual instruments.

The task of translation must have been a mammoth one and it has been carried through with devotion and dedication by $\mathrm{Mr}$. Auerbach. The opportunity has also been taken to correct certain errors in the original French edition. It is perhaps a little disappointing that the opportunity was not also taken to add a bibliography, an omission from the French text which could no doubt be attributed, in part at least, to the conditions prevailing when the book was first written.

W. D. WRIGHT

\section{ROGER JOSEPH BOSCOVICH}

Roger Joseph Boscovich, S.J., F.R.S., 1711-1787 Studies of his Life and Work on the 250th Anniversary of his Birth. Edited by Lancelot Law Whyte. Pp. $230+4$ plates. (London: George Allen and Unwin, Ltd., 1961.) 32s. net.

$T$ is doubtful whether the reputation of any other natural philosopher of the first rank has suffered such an undeserved eclipse as that of Roger Joseph Boscovich, S.J. Nor is the word 'eclipse' an idle metaphor; for less than fifty years ago this luminary shone with a light undiminished by the passage of a century. As late as $1905 \mathrm{~J}$. J. Thomson drew inspiration from the 'Boscovichian curve'; two years earlier Kelvin had described his own position as 'Boscovichian'; Maxwell gave a critical exposition of his theory in the article "Atom" in the Encyclopaedia Britannica, and in his Dynamical Theory of Gases based his argument on a mutual 'repulsion' of mass. points (his attribution of actual mass to Boscovich's 'puncta' was in fact an error); Faraday regarded Boscovich's point-centres of force as the only plausible form of 'atomicity', from which he turned away only as his own conception of the field came to dominate his thought; John Robison gave a long and careful exposition of Boscovich's theory from the chair of natural philosophy in Edinburgh in the closing years of the eighteenth century; and, finally, so struck was Priestley by the importance of Boscovich's ideas that he wrote to him with the view of having the Philosophiae naturalis theoria redacta ad unicam legem virium in natura existentium (Vienna 1758; revised, Venice 1763) translated.

Despite this cloud of witnesses, and the existence since 1922 of J. M. Child's fine translation of the Theoria, it is not uncommon to meet scientists who have not even heard of Boscovich. Fellows of the Royal Society were reminded of the exploits of their former colleague by Mr. L. L. Whyte's article in Notes and Records $(13,38)$; the book of studies now extends this opportunity to the general public: and there is scarcely any member of that public, now increasingly avid for reconstructions of the past, who would not derive pleasure and profit from its perusal.

Most of the articles make no very great claims on the technical equipment of the reader: the admirable "Biographical Essay" by Prof. Elizabeth Hill may be read with enjoyment and profit at almost any level of historical sophistication; for it deals with a fascinating and critical period of European history into the diplomatic, dynastic and ecclesiastical coulisses of which the young Jugoslav Jesuit was drawn by his urbane manner (at least in his early years), sympathetic understanding of human relations, elegant Latinity, and capacity for sustained hard work; while his technical realism brought him into consultation about the Pontine Marshes, the dome of St. Peter's, canals, cartography, geodesy, and the equipment of the Brera Observatory near Milan. He 